\title{
Emerging Stem Cell Therapies: Treatment, Safety, and Biology
}

\author{
Joel Sng and Thomas Lufkin \\ Stem Cell and Developmental Biology, Genome Institute of Singapore, 60 Biopolis Street, Singapore 138672 \\ Correspondence should be addressed to Thomas Lufkin, lufkin@gis.a-star.edu.sg
}

Received 4 May 2012; Revised 3 July 2012; Accepted 4 July 2012

Academic Editor: Erdal Karaöz

Copyright (C) 2012 J. Sng and T. Lufkin. This is an open access article distributed under the Creative Commons Attribution License, which permits unrestricted use, distribution, and reproduction in any medium, provided the original work is properly cited.

\begin{abstract}
Stem cells are the fundamental building blocks of life and contribute to the genesis and development of all higher organisms. The discovery of adult stem cells has led to an ongoing revolution of therapeutic and regenerative medicine and the proposal of novel therapies for previously terminal conditions. Hematopoietic stem cell transplantation was the first example of a successful stem cell therapy and is widely utilized for treating various diseases including adult T-cell leukemia-lymphoma and multiple myeloma. The autologous transplantation of mesenchymal stem cells is increasingly employed to catalyze the repair of mesenchymal tissue and others, including the lung and heart, and utilized in treating various conditions such as stroke, multiple sclerosis, and diabetes. There is also increasing interest in the therapeutic potential of other adult stem cells such as neural, mammary, intestinal, inner ear, and testicular stem cells. The discovery of induced pluripotent stem cells has led to an improved understanding of the underlying epigenetic keys of pluripotency and carcinogenesis. More in-depth studies of these epigenetic differences and the physiological changes that they effect will lead to the design of safer and more targeted therapies.
\end{abstract}

\section{Introduction}

Mammals are complex organisms populated by a cosmopolitan city of cells. Resembling the individual components of a metropolis, cells are the essential building blocks of all tissues and organs in an organism, ranging from the delicate construction of the inner ear to the sturdy femur. Like bricks in a skyscraper, the identity, role, and position of each cell must be carefully regulated to ensure the development of functional organs. However while buildings have to be designed and constructed, some bricks in each multicellular organism can mediate self-renewal and are commonly identified as stem cells (SCs). Embryonic SCs (ESCs) are pluripotent progenitors that retain the capacity to form cells from the three germ layers. These cells rely on a group of transcription factors that regulate a network of genes required for their maintenance and proliferation. Of these transcription factors, the activity of Sox2, Oct4, Nanog, and Klf4 is most critical for the maintenance of ESCs [1-3]. Sox2 is a member of the SRY-related HMB-box family and maintains ESC pluripotency by inducing Oct4 expression [4]. Oct 4 and Sox 2 coexpression then induces the formation of binary complexes that bind to their respective enhancer elements for positive self-regulation [5]. Oct4 also interacts with various Sox transcription factors like Sox2, Sox4, Sox11, and Sox 15 for coregulation of genes like Fgf4, Lefty1, Fbx15, Utf1, and Nanog via Oct-Sox enhancers [4, 6-11]. Nanog is a homeobox gene which is initially expressed monoallelically in 2-8 cell stage blastomeres and biallelically expressed only in the pluripotent inner cell mass as the embryo matures [12]. Hence monoallelic Nanog expression seems to en- courage differentiation while biallelic Nanog expression maintains pluripotency and is a key regulator in early embryonic development. Klf4 assists Oct4 and Sox2 in regulating various genes including Lefty 1 expression, maintains stem cell pluripotency, and has been implicated in differentiation and proliferation [11, 13-16]. Further validating the importance of these transcription factors, experiments have shown that the overexpression of Sox2, Oct4, and Klf4 can initiate the reprogramming of adult differentiated cells into Nanog expressing induced pluripotent stem cells (iPSCs) [17].

\section{Induced Pluripotent Stem Cells}

Since the pioneering experiments that demonstrated the possibility of inducing iPSCs from mouse fibroblasts via retroviral transduction in 2006, increasing interest in iPSCs has led to the discovery of other alternative methods for producing iPSCs [18]. Transduction via retroviral and lentiviral 
vectors was among the first methods for generating iPSCs [19-21]. However notable disadvantages of these widely used protocols are that the process results in integration of exogenous genetic material, such as the protooncogenes $c-M y c$, in transformed iPSCs which may increase the risk of tumorigenesis in iPSC-based therapies and the low transformation efficiency of adult cells to iPSCs (0.001-2\%) [22]. More recently, transfection of modified mRNA has been shown to reprogram fibroblasts to iPSCs with an efficiency of up to $4.4 \%$ without genomic integration of extracellular DNA [23]. More research into miRNA sequences has also led to the identification of the miR302/367 cluster which, when combined with lentiviral transduction, demonstrated $10 \%$ efficiency for reprogramming fibroblasts to iPSCs [24]. These improvements for generating iPSCs could lead to the development of a higher throughput system to obtain stem cells that more closely resemble adult stem cells and ESCs.

The utilization of iPSCs in therapy design and research possesses several distinct advantages over ESCs. Firstly since iPSCs are derived from the patient, there will be a reduced risk of immune rejection compared to allografts or xenografts from ESCs. In addition, it is easier to obtain iPSC precursors from patients compared to the difficulty and ethical concerns associated with the derivation of ESCs. Finally iPSCs are epigenetically different from ESCs and retain predisposition to redifferentiate into their original cell type [25]. This iPSC epigenetic memory could be harnessed to generate cell-specific types that cannot be easily obtained from ESCs.

The reprogramming of iPSCs from normal somatic cells necessitates a complex epigenetic transformation. To appropriately design the perfect iPSC, it is essential to gain a better understanding of epigenetic differences between iPSCs and ESCs. Recent research has provided insight into the epigenetic memory of iPSCs, a signature artifact from parental cells and the reprogramming process which restricts the ability of iPSCs to differentiate and form cells from alternative lineages $[25,26]$. These iPSC epigenetic signatures such as differences in CG methylation and histone modification near developmental control genes can be transmitted to their progeny even after differentiation and may affect the function of iPSC-derived cells [27]. Additionally, the role of chromatin-modifying enzymes has also been shown to influence the effectiveness of iPSC reprogramming and is essential for determining cell fate $[28,29]$. Hence the residual epigenetic memory of iPSCs has to be completely reset to resemble ESCs before they can be classified as truly pluripotent stem cells. Some molecular and environmental tools which can assist in epigenetic alteration include compounds like sodium butyrate which can modify H3K9 acetylation and $\mathrm{CpG}$ demethylation of specific promoters regulating various genes (Dppa5, Ddx43, Rcn3, Sp5) [30], DNA methyltransferase inhibitors (e.g., valproic acid, 5-aza-cytidine) which can be designed to inhibit specific methyltransferases for overcoming barriers to DNA methylation reprogramming [31, 32], antioxidant mixtures (e.g., Withania somnifera extract), and kinase inhibitors (e.g., tyrosine kinase inhibitors) which can inhibit phosphorylation of various genes $[33,34]$. Standardizing the in vitro microenvironment for cultured stem cells is also essential for generating the desired epigenetic expression. Owing to the different culture conditions in various laboratories, even similar stem cell lines can exhibit heterogeneous genetic expression. Greater differences in gene expression exist between various iPSCs and ESCs lines as they can exhibit epigenetic differences even when cultured under similar conditions $[35,36]$. Hence close regulation of the in vitro microenvironment will be necessary for proper epigenetic control and maintain stem cell epigenetic homogeneity as even varying oxygen levels alone can induce epigenetic changes that facilitate reprogramming to iPSCs and their directed differentiation $[37,38]$. However although a repertoire of epigenetic tools are available, additional research to identify and map the epigenetic ground state of ESCs will be essential for their proper application to reset these inherent iPSC signatures.

Genetic mutations and differences inherent in both iPSCs and other stem cells cultured in in vitro conditions also have to be evaluated before they can be safely utilized in medical therapies. While some studies have indicated that a subset of stem cells such as mesenchymal stem cells are able to maintain genetic stability for up to six months [39, 40], more recent larger-scale studies have demonstrated a predisposition to genetic instability and overexpression of protooncogenes in cultured stem cells due to selective pressures of culture conditions and the consequences of reprogramming to produce iPSCs $[41,42]$. Hence more research has to be conducted to determine optimal stem cell culture conditions to prevent undesired genetic abbreviations from occurring. It is also essential to develop reprogramming protocols that generate genetically stable iPSCs. Finally the genetic integrity of all stem cells should be verified before they are utilized in therapies so as to reduce the chance of tumorigenesis in patients.

\section{Adult Stem Cell Therapies}

Despite the limitations in understanding stem cell differentiation and iPSC reprogramming, there has been some progress in verifying the safety of adult stem-cell-based therapies for several diseases. This process is important because many genes activated in stem cells or considered useful in inducing iPSC formation are protooncogenes, and this raises the possibility that stem-cell-based therapies may increase the risk of cancer in patients. For example, the four transcription factors commonly utilized in iPSC reprogramming Sox2, Oct4, Nanog, and Klf4 have been linked to carcinogenesis, increased cancer malignancy and tumor drug resistance and are overexpressed in many cancers and cancer stem cells [43-51]. Additionally the inactivation of tumor suppressor genes like $p 53$ exhibits similar effects by encouraging iPSC formation at the expense of increased risk of tumorigenesis and genetic instability [52].

\section{Mesenchymal Stem Cells}

Multiple studies have been conducted in an attempt to verify the safety and effectiveness of various stem cell therapies. 
Some of these successful studies utilize adult stem cells such as bone-marrow-derived mesenchymal stem cells (MSCs) in trials of various regenerative therapies. These cells were first described as MSCs due to their ability to differentiate and form various mesenchymal cells such as bone and cartilage cells [53]. MSCs form a surprisingly heterogeneous cell population, and the subset of MSCs extracted from bone marrow alone displays a wide variety of cellular morphologies and antigen markers [54]. Human-marrowderived MSC autografts were one of the first successes in stem cell therapies as there is minimal chance of immune rejection due to their intrinsic immunomodulatory properties [55]. In addition, these MSC transplantations do not typically result in teratoma formation when tested in clinical trials and are relatively safe compared to ESCs and iPSCs which readily form teratomas [56]. In one such study, 41 patients who underwent bone-marrow-derived MSC transplant for joint repair were examined for tumor and infection symptoms for between 5 and 137 months, and no abnormalities were detected [57]. Another study of MSC transplantation for orthopedic therapy involving several hundred patients over a period of 1-2 years also argues that these transplantations are unlikely to increase the risk of carcinogenesis [58]. Other studies have also indicated that MSC transplantation is safe and has led to improved prognosis for orthopedic ailments $[59,60]$. The safety of MSCs therapies for myocardial infarction has also been accessed, and patients show improved cardiovascular prognosis [61]. MSCs have also been utilized in organogenesis for lung reconstruction. In one study patient's MSCs and epithelial cells were combined with donated trachea cartilage in a bioreactor to form a functional graft that was then successfully used to rescue patient lung function without immune rejection [62]. More recently, improved tissue engineering methods have reduced the time required for graft generation from 3 months to 3 weeks allowing patients requiring more urgent transplants to be treated [63]. Besides their role in bone and cartilage repair, other MSC-based therapies have also been evaluated for their safety and varying levels of effectiveness for treating various conditions including stroke, multiple sclerosis, diabetes, and kidney transplantation, in other clinical trials [64-68].

MSCs can also be extracted from adipose and synovial tissues, peripheral blood, skeleton muscles, and neonatal tissues like the umbilical cord [69]. Adipose tissue is a rich source of MSCs which have been used to stimulate the regeneration of bones and cartilage tissues in humans and can partially mediate the effects of osteoarthritis and osteonecrosis [70]. The use of adipose MSCs is advantageous as they can be readily extracted via liposuction of adipose tissue which is a minimally invasive procedure and purified via established protocols $[71,72]$. Hence adipose MSCs could be considered as a viable source of stem cells if the patient is unable to undergo bone marrow MSC extraction. MSCs can also be isolated from synovial fluid in humans and animals [73]. Initial exploratory studies in rabbits have proven that treatment with synovial MSCs can prevent degeneration of the intervertebral disc [74]. In addition some studies have argued that synovial MSCs may have greater therapeutic effects compared to MSCs derived from other sources due to an increased ability to proliferate, differentiate, attach to damaged tissue, and accelerate healing in animal models [75-77]. Some progress has also been made in engineering in vitro tissue constructs to expedite implantation of synovial MSCs [78].

While MSCs extracted from different regions exhibit similar differentiation potential and therapeutic effect, some distinct traits do exist. Human MSCs derived from marrow express different cellular markers from adipose MSCs. For example, adipose MSCs express higher levels of CD49d, CD34, and CD54 while marrow MSCs express higher levels of CD106 [79]. These naturally occurring differences in homing and mobilization markers could be exploited for more targeted stem cell therapies. The differentiation potential of MSCs also varies. For example, while marrowderived MSCs have a higher chondrogenic potential, adipose MSCs differentiate to form cardiomyocytes more readily $[80,81]$. More in-depth studies of these phenomena could reveal the epigenetic regulators that prime stem cell differentiation and homing and increase the repertoire of tools available to control stem cell specificity, differentiation, and proliferation. Further clinical trials will need to be carried out to verify the therapeutic effectiveness and safety of MSCbased therapies in humans.

\section{Hematopoietic Stem Cells}

Hematopoietic stem cells (HSCs) have also been widely utilized in experimental therapies with pioneering studies of HSC transplantation (HSCT) dating back to the 1950s [82]. HSCs consist of a surprisingly heterogeneous population of multipotent stem cells which collectively possess the potential to form all blood cell types [83]. HSCs can be purified from bone marrow cells by selecting for cells possessing various expression markers like membrane glycoprotein Sca1 and tyrosine kinase receptor c-Kit (CD117) and lacking terminal differentiation markers [84]. HSCT is most commonly utilized in therapy for various blood- and bone-marrowrelated cancers such as leukemia and multiple myeloma. A retrospective analysis of 586 adult T-cell leukemialymphoma patients who received allogeneic hematopoietic stem cell transplantation revealed that HSC therapy was effective for improving long-term survival in these patients [85]. Multiple myeloma has also been successfully treated with a combination of HSCT, chemotherapy, and total body irradiation since 1986 [86, 87]. The development of combination HSCT therapies involving newer drugs like lenalidomide, pegylated liposomal doxorubicin, dexamethasone, and bortezomib continues to improve progressionfree survival and overall survival rates of these patients [8891]. However although allogeneic HSCT can improve patient survival and cancer remission through the induction of acute graft-versus-tumor effect (GVT), this process remains poorly understood and may involve various transplanted cell types including T cells, natural killer cells, and B cells $[92,93]$. In addition, although full donor chimerism after HSCT reduces the risk of cancer relapse and progression, HSCT is also associated with several negative side effects 
including graft-versus-host disease (GVHD) which may lead to lethal complications in patients $[86,92]$. HSCT patients with chronic GVHD may also be more likely to suffer from secondary tumors such as basal cell skin cancer, oral squamous cell carcinoma, sarcoma, and adenocarcinoma $[94,95]$.

HSCT has also been tested in other experimental therapies including lysosomal storage diseases and other metabolic diseases such as Hurler syndrome and X-linked adrenoleukodystrophy leading to improved patient survival rates [96-98]. Recently, HSCT involving a CCR5 $\delta 32$ homozygous donor also resulted in the first successful cure of HIV and has renewed interest in the search of a remedy for this chronic epidemic which has contributed to over 30 million deaths worldwide [99]. In summary, although recent advances in surgical techniques and drug regimens have led to improved HSCT survival rates and disease remission in patients, potential complications related to HSCT have restricted its use to patients with life-threatening diseases. Hence further studies will be essential for enhancing the safety and effectiveness of HSCT. In particular, a better understanding of how the positive effects of GVT can be enhanced and separated from negative side effects like GVHD could lead to major breakthroughs in currently available therapies.

\section{Neural Stem Cells}

The therapeutic potential of neural stem cells (NSCs) has also received considerable interest. Studies have proven that NSCs can be isolated from the mouse bone marrow, striatum, and NSC lines with a stable chromosome number and have also been generated from human iPSCs [100-103]. In addition, NSCs can be reprogrammed into iPSCs by Oct4 overexpression to generate other cell types [104]. However some studies have proposed that NSCs may be predisposed to culture-induced mutations that could limit their therapeutic utility $[105,106]$. Hence more studies should be undertaken to identify suitable in vitro culture conditions for maintaining NSC genetic and epigenetic stability. Due to these limitations, evaluations of the therapeutic effectiveness of NSCs have mainly been performed in animal trials. Several of these studies have documented the effectiveness of NSCs for alleviating the symptoms of multiple sclerosis in experimental autoimmune encephalomyelitis (EAE) mouse models. These studies indicate that NSCs are able to enter the central nervous system, form brain cells, promote neuroprotection, and encourage remyelination [107-110]. A closer look into the role of NSCs in adaptive immune regulation has also revealed that NSCs release a morphogen (bone morphogenetic protein 4) which prevents dendritic cell maturation and reduces the formation of antigenspecific $\mathrm{T}$ cells resulting in limited neuroprotection in EAE mouse models [111]. Further experiments involving transplanting NSCs engineered to produce IL-10 have also demonstrated their enhanced potential for enhancing their immune-suppressive effect for mediating the progress of EAE compared to NSC transplantation alone [112].
The study of how endogenous NSCs can be encouraged to mediate repair has also received considerable interest. NSCs exist in specific stem cell niches in adult mammals such as the ependymal layer and can migrate and differentiate to form functional neural cells in rat EAE models $[113,114]$. These ependymal-derived NSCs can also differentiate to form supporting cells like astrocytes and oligodendrocytes $[115,116]$. The endogenous NSC-based repair mechanism is governed by complex molecular pathways involving morphogens, neurotransmitters, growth factors, transcription factors, cell surface molecules, and nuclear orphan receptors (for review see [117]). Future minimally invasive regenerative therapies may seek to utilize this endogenous source of NCSs by inducing genetic and pharmacologically directed cell migration and differentiation based on an improved understanding of these molecular pathways. NSCs have also been studied for their therapeutic effects in other neural diseases like fetal alcohol spectrum disorder and lysosomal storage diseases $[118,119]$, and scaffolds containing NSCs have also been shown to encourage recovery from spinal cord injury in Wistar rats [120].

\section{Other Adult Stem Cells}

Many other different categories of naturally occurring stem cells have been identified and investigated for their therapeutic potentials including, mammary stem cells, intestinal stem cells, inner ear stem cells, and testicular stem cells. Mammary stem cell concentration can be enriched by fluorescenceactivated cell sorting of mouse mammary glands for cells that are $\mathrm{CD} 31^{-}, \mathrm{CD} 45^{-}, \mathrm{Ter} 119^{-}, \mathrm{Sca}-1^{\text {low }}, \mathrm{CD} 24^{+}$, and either CD49f high or CD29high $[121,122]$. These multipotent mammary stem cells are able to form functional mammary glands when transplanted in mice, and human mammary stem cells have been isolated in an attempt to better understand carcinogenesis and cancer stem cells [121, 123]. Intestinal stem cells can mediate partial restoration of small intestine function after intestinal resection [124]. More studies to elucidate the molecular pathways regulating this regenerative mechanism may lead to the development of novel regenerative gene therapies for improved intestinal function in patients suffering from short bowel syndrome. Hearing loss due to the loss of cochlea hair cells is another ailment that could be treated with stem cell therapy. In the search for a cure, inner ear stem cells have been identified in both the dorsal epithelium of the cochlear canal and the adult utricular sensory epithelium $[125,126]$. These ongoing studies point to an ongoing attempt to identify potential progenitors for hearing restoration and the molecular regulators that guide this process. Testicular stem cell transplantation has been successfully used to restore fertility in mice, pig, and goat animal models and assist in the creation of transgenic animals [127-129]. Further advances in this area may result in therapies for preserving the fertility of cancer patients who are infertile due to the side effects of chemotherapy and radiation therapies. In conclusion these studies demonstrate that while ensuring the safety of adult stem cell therapies remains a key concern, the inherent 
regenerative capacity of the adult stem cell reservoir can be leveraged to augment the effectiveness of existing medical remedies.

\section{Conclusion}

While the field of stem cell medicine is rapidly maturing, many potential stem cell therapies remain theoretical or restricted to successes in animal trials which may not translate directly to safe human stem cell therapies. In addition, a notable limitation of human clinical trials involving stem cell therapies is that they often only involve a small group of patients or that the studies were conducted over a short period of several years which may be insufficient to access the true risks of carcinogenesis. Hence the results may not be accurate when extrapolated to determine the longterm safety and effectiveness of these therapies in a larger population. Therefore stem cell therapies should continue to be utilized only as a last resort when conventional therapies have failed or are unavailable, and the condition and response of patients undergoing these therapies should be assessed at regular intervals to ensure their safety.

It is also important to note that many currently utilized stem cell therapies and clinical trials have limited impact on alleviating disease symptoms. This is because most current therapies only attempt to treat one aspect of the disease. In addition a limited ability to diagnose the varied underlying causes of similar disease symptoms and the lack of tests to identify the complex differences between individual patients have led to the application of a generic therapy to a heterogeneous population of patients. Consequently better tools to determine the unique genetic and epigenetic factors in each patient that lead to each disease symptom are increasingly essential for maximizing the potential of customized stem cell therapies. Moreover combinational therapies capitalizing on the integration of various approaches such as stem cell transplantation, material science, gene therapy, developmental biology, and pharmacology for simultaneously targeting multiple aspects of each disease will progressively be required for developing next-generation therapies.

An improved understanding of the intracellular molecular pathways regulating stem cell differentiation and new methods to manipulate these pathways to maintain genetic stability induce desired epigenetic modifications, and phenotypic changes will also be essential for guaranteeing the safety and potency of future stem cell therapies. To achieve this, the myriad genetic and epigenetic variations in seemingly homogeneous stem cell populations have to be studied in greater detail, and the impact of each variation on differentiation, proliferation, and pluripotency must be quantified.

Finally a complete understanding of the mechanisms of stem cell signaling and intercellular communication, such as stromal cell-derived factor-1/CXC chemokine receptor-4 signaling for guiding hematopoietic stem cell mobilization, has to be elucidated [130]. Elucidating the language behind these molecular communications will enable the design of stem cells which can be guided to specific locations, evade potential immune rejection, and interact with host cells to accelerate tissue restoration. It will also lead to improvements in tissue engineering of more complex organs that require the precise positioning of many different cell types to function normally.

In conclusion it can be seen that although many pioneering discoveries have transformed the way we understand stem cell function, countless studies are still required on the expanding frontier of stem cell research before a complete mastery of stem cell manipulation for maximum therapeutic potential can be achieved.

\section{References}

[1] A. Martinez Arias and J. M. Brickman, "Gene expression heterogeneities in embryonic stem cell populations: origin and function," Current Opinion in Cell Biology, vol. 23, no. 6, pp. 650-656, 2011.

[2] A. A. Avilion, S. K. Nicolis, L. H. Pevny, L. Perez, N. Vivian, and R. Lovell-Badge, "Multipotent cell lineages in early mouse development depend on SOX2 function," Genes and Development, vol. 17, no. 1, pp. 126-140, 2003.

[3] K. Mitsui, Y. Tokuzawa, H. Itoh et al., "The homeoprotein Nanog is required for maintenance of pluripotency in mouse epiblast and ES cells," Cell, vol. 113, no. 5, pp. 631-642, 2003.

[4] S. Masui, Y. Nakatake, Y. Toyooka et al., "Pluripotency governed by Sox 2 via regulation of Oct3/4 expression in mouse embryonic stem cells," Nature Cell Biology, vol. 9, no. 6, pp. 625-635, 2007.

[5] J. L. Chew, Y. H. Loh, W. Zhang et al., "Reciprocal transcriptional regulation of Pouff1 and Sox2 via the Oct4/Sox2 complex in embryonic stem cells," Molecular and Cellular Biology, vol. 25, no. 14, pp. 6031-6046, 2005.

[6] Y. Tokuzawa, E. Kaiho, M. Maruyama et al., "Fbx15 is a novel target of Oct $3 / 4$ but is dispensable for embryonic stem cell self-renewal and mouse development," Molecular and Cellular Biology, vol. 23, no. 8, pp. 2699-2708, 2003.

[7] D. C. Ambrosetti, H. R. Schöler, L. Dailey, and C. Basilico, "Modulation of the activity of multiple transcriptional activation domains by the DNA binding domains mediates the synergistic action of Sox 2 and Oct- 3 on the fibroblast growth factor-4 enhancer," The Journal of Biological Chemistry, vol. 275, no. 30, pp. 23387-23397, 2000.

[8] M. Maruyama, T. Ichisaka, M. Nakagawa, and S. Yamanaka, "Differential roles for Sox15 and Sox2 in transcriptional control in mouse embryonic stem cells," The Journal of Biological Chemistry, vol. 280, no. 26, pp. 24371-24379, 2005.

[9] D. J. Rodda, J. L. Chew, L. H. Lim et al., "Transcriptional regulation of Nanog by OCT4 and SOX2," The Journal of Biological Chemistry, vol. 280, no. 26, pp. 24731-24737, 2005.

[10] M. Nishimoto, A. Fukushima, A. Okuda, and M. Muramatsu, "The gene for the embryonic stem cell coactivator UTF1 carries a regulatory element which selectively interacts with a complex composed of Oct-3/4 and Sox-2," Molecular and Cellular Biology, vol. 19, no. 8, pp. 5453-5465, 1999.

[11] Y. Nakatake, N. Fukui, Y. Iwamatsu et al., "Klf4 cooperates with Oct $3 / 4$ and Sox 2 to activate the Lefty 1 core promoter in embryonic stem cells," Molecular and Cellular Biology, vol. 26, no. 20, pp. 7772-7782, 2006.

[12] Y. Miyanari and M. E. Torres-Padilla, "Control of groundstate pluripotency by allelic regulation of Nanog," Nature, vol. 483, no. 7390, pp. 470-473, 2012. 
[13] M. O. Kim, S.-H. Kim, Y.-Y. Cho et al., "ERK1 and ERK2 regulate embryonic stem cell self-renewal through phosphorylation of Klf4," Nature Structural \& Molecular Biology, vol. 19, no. 3, pp. 283-290, 2012.

[14] E. M. Whitney, A. M. Ghaleb, X. Chen, and V. W. Yang, "Transcriptional profiling of the cell cycle checkpoint gene krüppel-like factor 4 reveals a global inhibitory function in macromolecular biosynthesis," Gene Expression, vol. 13, no. 2, pp. 85-96, 2006.

[15] X. Chen, E. M. Whitney, S. Y. Gao, and V. W. Yang, "Transcriptional profiling of krüppel-like factor 4 reveals a function in cell cycle regulation and epithelial differentiation," Journal of Molecular Biology, vol. 326, no. 3, pp. 665-677, 2003.

[16] B. D. Rowland, R. Bernards, and D. S. Peeper, "The KLF4 tumour suppressor is a transcriptional repressor of p53 that acts as a context-dependent oncogene," Nature Cell Biology, vol. 7, no. 11, pp. 1074-1082, 2005.

[17] M. Wernig, A. Meissner, J. P. Cassady, and R. Jaenisch, "c-Myc is dispensable for direct reprogramming of mouse fibroblasts," Cell Stem Cell, vol. 2, no. 1, pp. 10-12, 2008.

[18] K. Takahashi and S. Yamanaka, "Induction of pluripotent stem cells from mouse embryonic and adult fibroblast cultures by defined factors," Cell, vol. 126, no. 4, pp. 663-676, 2006.

[19] K. Takahashi, K. Tanabe, M. Ohnuki et al., "Induction of pluripotent stem cells from adult human fibroblasts by defined factors," Cell, vol. 131, no. 5, pp. 861-872, 2007.

[20] J. Yu, M. A. Vodyanik, K. Smuga-Otto et al., "Induced pluripotent stem cell lines derived from human somatic cells," Science, vol. 318, no. 5858, pp. 1917-1920, 2007.

[21] M. Stadtfeld, K. Brennand, and K. Hochedlinger, "Reprogramming of pancreatic $\beta$ cells into induced pluripotent stem cells," Current Biology, vol. 18, no. 12, pp. 890-894, 2008.

[22] D. A. Robinton and G. Q. Daley, "The promise of induced pluripotent stem cells in research and therapy," Nature, vol. 481, no. 7381, pp. 295-305, 2012.

[23] L. Warren, P. D. Manos, T. Ahfeldt et al., "Highly efficient reprogramming to pluripotency and directed differentiation of human cells with synthetic modified mRNA," Cell Stem Cell, vol. 7, no. 5, pp. 618-630, 2010.

[24] F. Anokye-Danso, C. M. Trivedi, D. Juhr et al., "Highly efficient miRNA-mediated reprogramming of mouse and human somatic cells to pluripotency," Cell Stem Cell, vol. 8, no. 4, pp. 376-388, 2011.

[25] K. Kim, A. Doi, B. Wen et al., "Epigenetic memory in induced pluripotent stem cells," Nature, vol. 467, no. 7313, pp. 285290, 2010.

[26] O. Bar-Nur, H. A. Russ, S. Efrat, and N. Benvenisty, "Epigenetic memory and preferential lineage-specific differentiation in induced pluripotent stem cells derived from human pancreatic islet beta cells," Cell Stem Cell, vol. 9, no. 1, pp. 17-23, 2011.

[27] R. Lister, M. Pelizzola, Y. S. Kida et al., "Hotspots of aberrant epigenomic reprogramming in human induced pluripotent stem cells," Nature, vol. 471, no. 7336, pp. 68-73, 2011.

[28] T. T. Onder, N. Kara, A. Cherry et al., "Chromatin-modifying enzymes as modulators of reprogramming," Nature, vol. 483, no. 7391, pp. 598-602, 2012.

[29] R. M. Barrett and M. A. Wood, "Beyond transcription factors: the role of chromatin modifying enzymes in regulating transcription required for memory," Learning and Memory, vol. 15 , no. 7, pp. 460-467, 2008.
[30] C. B. Ware, L. Wang, B. H. Mecham et al., "Histone deacetylase inhibition elicits an evolutionarily conserved selfrenewal program in embryonic stem cells," Cell Stem Cell, vol. 4, no. 4, pp. 359-369, 2009.

[31] G. Hobley, J. C. McKelvie, J. E. Harmer et al., "Development of rationally designed DNA N6 adenine methyltransferase inhibitors," Bioorganic \& Medicinal Chemistry Letters, vol. 22, no. 9, pp. 3079-3082, 2012.

[32] B. Feng, J. H. Ng, J. C. D. Heng, and H. H. Ng, "Molecules that promote or enhance reprogramming of somatic cells to induced pluripotent stem cells," Cell Stem Cell, vol. 4, no. 4, pp. 301-312, 2009.

[33] H. Nakajima, K. Fukazawa, Y. Wakabayashi et al., "Withania somnifera extract attenuates stem cell factor-stimulated pigmentation in human epidermal equivalents through interruption of ERK phosphorylation within melanocytes," Journal of Natural Medicines, vol. 66, no. 3, pp. 435-446, 2012.

[34] I. Posner, M. Engel, A. Gazit, and A. Levitzki, "Kinetics of inhibition by tyrphostins of the tyrosine kinase activity of the epidermal growth factor receptor and analysis by a new computer program," Molecular Pharmacology, vol. 45, no. 4, pp. 673-683, 1994.

[35] A. M. Newman and J. B. Cooper, "Lab-specific gene expression signatures in pluripotent stem cells," Cell Stem Cell, vol. 7, no. 2, pp. 258-262, 2010.

[36] M. H. Chin, M. J. Mason, W. Xie et al., "Induced pluripotent stem cells and embryonic stem cells are distinguished by gene expression signatures," Cell Stem Cell, vol. 5, no. 1, pp. 111123, 2009.

[37] D. Bae, P. Mondragon-Teran, D. Hernandez et al., "Hypoxia enhances the generation of retinal progenitor cells from human induced pluripotent and embryonic stem cells," Stem Cells and Development, vol. 21, no. 8, pp. 1344-1355, 2012.

[38] Y. Yoshida, K. Takahashi, K. Okita, T. Ichisaka, and S. Yamanaka, "Hypoxia enhances the generation of induced pluripotent stem cells," Cell Stem Cell, vol. 5, no. 3, pp. 237241, 2009.

[39] M. E. Bernardo, N. Zaffaroni, F. Novara et al., "Human bone marrow-derived mesenchymal stem cells do not undergo transformation after long-term in vitro culture and do not exhibit telomere maintenance mechanisms," Cancer Research, vol. 67, no. 19, pp. 9142-9149, 2007.

[40] L. A. Meza-Zepeda, A. Noer, J. A. Dahl, F. Micci, O. Myklebost, and P. Collas, "High-resolution analysis of genetic stability of human adipose tissue stem cells cultured to senescence," Journal of Cellular and Molecular Medicine, vol. 12, no. 2, pp. 553-563, 2008.

[41] U. Ben-David, Y. Mayshar, and N. Benvenisty, "Large-scale analysis reveals acquisition of lineage-specific chromosomal aberrations in human adult stem cells," Cell Stem Cell, vol. 9, no. 2, pp. 97-102, 2011.

[42] U. Ben-David, N. Benvenisty, and Y. Mayshar, "Genetic instability in human induced pluripotent stem cells: classification of causes and possible safeguards," Cell Cycle, vol. 9, no. 23, pp. 4603-4604, 2010.

[43] J. Neumann, F. Bahr, D. Horst et al., "SOX2 expression correlates with lymph-node metastases and distant spread in right-sided colon cancer," BMC Cancer, vol. 11, p. 518, 2011.

[44] O. Leis, A. Eguiara, E. Lopez-Arribillaga et al., "Sox2 expression in breast tumours and activation in breast cancer stem cells," Oncogene, vol. 31, no. 11, pp. 1354-1365, 2012. 
[45] D. E. Linn, X. Yang, F. Sun et al., "A role for OCT4 in tumor initiation of drug-resistant prostate cancer cells," Genes and Cancer, vol. 1, no. 9, pp. 908-916, 2010.

[46] S. H. Chiou, M. L. Wang, Y. T. Chou et al., "Coexpression of Oct4 and Nanog enhances malignancy in lung adenocarcinoma by inducing cancer stem cell-like properties and epithelial-mesenchymal transdifferentiation," Cancer Research, vol. 70, no. 24, pp. 10433-10444, 2010.

[47] M. Gazouli, M. G. Roubelakis, G. E. Theodoropoulos et al., "OCT4 spliced variant OCT4B1 is expressed in human colorectal cancer," Molecular Carcinogenesis, vol. 51, no. 2, pp. 165-173, 2012.

[48] M. H. Asadi, S. J. Mowla, F. Fathi, A. Aleyasin, J. Asadzadeh, and Y. Atlasi, "OCT4B1, a novel spliced variant of OCT4, is highly expressed in gastric cancer and acts as an antiapoptotic factor," International Journal of Cancer, vol. 128, no. 11, pp. 2645-2652, 2011.

[49] J. Shan, J. Shen, L. Liu et al., "Nanog regulates selfrenewal of cancer stem cell through IGF pathway in human hepatocellular carcinoma," Hepatology. In press.

[50] R. Hu, Y. Zuo, L. Zuo et al., "KLF4 expression correlates with the degree of differentiation in colorectal cancer," Gut and Liver, vol. 5, no. 2, pp. 154-159, 2011.

[51] A. Y. Pandya, L. I. Talley, A. R. Frost et al., "Nuclear localization of KLF4 is associated with an aggressive phenotype in early-stage breast cancer," Clinical Cancer Research, vol. 10, no. 8, pp. 2709-2719, 2004.

[52] V. Krizhanovsky and S. W. Lowe, "Stem cells: the promises and perils of p53," Nature, vol. 460, no. 7259, pp. 1085-1086, 2009.

[53] A. I. Caplan, "Mesenchymal stem cells," Journal of Orthopaedic Research, vol. 9, no. 5, pp. 641-650, 1991.

[54] M. Pevsner-Fischer, S. Levin, and D. Zipori, "The origins of mesenchymal stromal cell heterogeneity," Stem Cell Reviews and Reports, vol. 7, no. 3, pp. 560-568, 2011.

[55] A. J. Nauta and W. E. Fibbe, "Immunomodulatory properties of mesenchymal stromal cells," Blood, vol. 110, no. 10, pp. 3499-3506, 2007.

[56] P. S. Knoepfler, "Deconstructing stem cell tumorigenicity: a roadmap to safe regenerative medicine," Stem Cells, vol. 27, no. 5, pp. 1050-1056, 2009.

[57] S. Wakitani, T. Okabe, S. Horibe et al., "Safety of autologous bone marrow-derived mesenchymal stem cell transplantation for cartilage repair in 41 patients with 45 joints followed for up to 11 years and 5 months," Journal of Tissue Engineering and Regenerative Medicine, vol. 5, no. 2, pp. 146150, 2011.

[58] C. J. Centeno, J. R. Schultz, M. Cheever et al., "Safety and complications reporting update on the re-implantation of culture-expanded mesenchymal stem cells using autologous platelet lysate technique," Current Stem Cell Research \& Therapy, vol. 6, no. 4, pp. 368-378, 2011.

[59] H. S. Varma, B. Dadarya, and A. Vidyarthi, "The new avenues in the management of osteo-arthritis of knee-stem cells," Journal of the Indian Medical Association, vol. 108, no. 9, pp. 583-585, 2010.

[60] S. Wakitani, M. Nawata, K. Tensho, T. Okabe, H. Machida, and H. Ohgushi, "Repair of articular cartilage defects in the patello-femoral joint with autologous bone marrow mesenchymal cell transplantation: three case reports involving nine defects in five knees," Journal of Tissue Engineering and Regenerative Medicine, vol. 1, no. 1, pp. 74-79, 2007.

[61] J. M. Hare, J. H. Traverse, T. D. Henry et al., "A randomized, double-blind, placebo-controlled, dose-escalation study of intravenous adult human mesenchymal stem cells (prochymal) after acute myocardial infarction," Journal of the American College of Cardiology, vol. 54, no. 24, pp. 22772286, 2009.

[62] P. Macchiarini, P. Jungebluth, T. Go et al., "Clinical transplantation of a tissue-engineered airway," The Lancet, vol. 372, no. 9655, pp. 2023-2030, 2008.

[63] S. Baiguera, P. Jungebluth, A. Burns et al., "Tissue engineered human tracheas for in vivo implantation," Biomaterials, vol. 31, no. 34, pp. 8931-8938, 2010.

[64] J. Tan, W. Wu, X. Xu et al., "Induction therapy with autologous mesenchymal stem cells in living-related kidney transplants: a randomized controlled trial," The Journal of the American Medical Association, vol. 307, no. 11, pp. 11691177, 2012.

[65] P. Connick, M. Kolappan, C. Crawley et al., "Autologous mesenchymal stem cells for the treatment of secondary progressive multiple sclerosis: an open-label phase 2a proofof-concept study," The Lancet Neurology, vol. 11, no. 2, pp. 150-156, 2012.

[66] R. Jiang, Z. Han, G. Zhuo et al., "Transplantation of placentaderived mesenchymal stem cells in type 2 diabetes: a pilot study," Frontiers of Medicine, vol. 5, no. 1, pp. 94-100, 2011.

[67] C. Siatskas, N. L. Payne, M. A. Short et al., "A consensus statement addressing mesenchymal stem cell transplantation for multiple sclerosis: it's time!," Stem Cell Reviews and Reports, vol. 6, no. 4, pp. 500-506, 2010.

[68] J. S. Lee, J. M. Hong, G. J. Moon, P. H. Lee, Y. H. Ahn, and O. Y. Bang, "A long-term follow-up study of intravenous autologous mesenchymal stem cell transplantation in patients with ischemic stroke," Stem Cells, vol. 28, no. 6, pp. 1099-1106, 2010.

[69] Y. Zhang, D. Khan, J. Delling et al., "Mechanisms underlying the osteo- and adipo-differentiation of human mesenchymal stem cells," The Scientific World Journal, vol. 2012, Article ID 793823, 14 pages, 2012.

[70] J. Pak, "Regeneration of human bones in hip osteonecrosis and human cartilage in knee osteoarthritis with autologous adipose-tissue-derived stem cells: a case series," Journal of Medical Case Reports, vol. 5, p. 296, 2011.

[71] S. Schreml, P. Babilas, S. Fruth et al., "Harvesting human adipose tissue-derived adult stem cells: resection versus liposuction," Cytotherapy, vol. 11, no. 7, pp. 947-957, 2009.

[72] S. G. Dubois, E. Z. Floyd, S. Zvonic et al., "Isolation of human adipose-derived stem cells from biopsies and liposuction specimens," Methods in Molecular Biology, vol. 449, pp. 6979, 2008.

[73] N. Koyama, Y. Okubo, K. Nakao et al., "Pluripotency of mesenchymal cells derived from synovial fluid in patients with temporomandibular joint disorder," Life Sciences, vol. 89, no. 19-20, pp. 741-747, 2011.

[74] T. Miyamoto, T. Muneta, T. Tabuchi et al., "Intradiscal transplantation of synovial mesenchymal stem cells prevents intervertebral disc degeneration through suppression of matrix metalloproteinase-related genes in nucleus pulposus cells in rabbits," Arthritis Research \& Therapy, vol. 12, no. 6, article R206, 2010.

[75] Y. Sakaguchi, I. Sekiya, K. Yagishita, and T. Muneta, "Comparison of human stem cells derived from various mesenchymal tissues: superiority of synovium as a cell source," Arthritis and Rheumatism, vol. 52, no. 8, pp. 25212529, 2005.

[76] Y. J. Ju, T. Muneta, H. Yoshimura, H. Koga, and I. Sekiya, "Synovial mesenchymal stem cells accelerate early 
remodeling of tendon-bone healing," Cell and Tissue Research, vol. 332, no. 3, pp. 469-478, 2008.

[77] I. Sekiya, T. Muneta, H. Koga et al., "Articular cartilage regeneration with synovial mesenchymal stem cells," Clinical Calcium, vol. 21, no. 6, pp. 879-889, 2011.

[78] W. Ando, K. Tateishi, D. Katakai et al., "In vitro generation of a scaffold-free tissue-engineered construct (TEC) derived from human synovial mesenchymal stem cells: biological and mechanical properties and further chondrogenic potential," Tissue Engineering A, vol. 14, no. 12, pp. 2041-2049, 2008.

[79] D. A. De Ugarte, Z. Alfonso, P. A. Zuk et al., "Differential expression of stem cell mobilization-associated molecules on multi-lineage cells from adipose tissue and bone marrow," Immunology Letters, vol. 89, no. 2-3, pp. 267-270, 2003.

[80] J. I. Huang, N. Kazmi, M. M. Durbhakula, T. M. Hering, J. U. Yoo, and B. Johnstone, "Chondrogenic potential of progenitor cells derived from human bone marrow and adipose tissue: a patient-matched comparison," Journal of Orthopaedic Research, vol. 23, no. 6, pp. 1383-1389, 2005.

[81] J. Yang, T. Song, P. Wu et al., "Differentiation potential of human mesenchymal stem cells derived from adipose tissue and bone marrow to sinus node-like cells," Molecular Medicine Reports, vol. 5, no. 1, pp. 108-113, 2012.

[82] E. D. Thomas, H. L. Lochte, W. C. Lu, and J. W. Ferrebee, "Intravenous infusion of bone marrow in patients receiving radiation and chemotherapy," The New England Journal of Medicine, vol. 257, no. 11, pp. 491-496, 1957.

[83] C. E. Müller-Sieburg, R. H. Cho, M. Thoman, B. Adkins, and H. B. Sieburg, "Deterministic regulation of hematopoietic stem cell self-renewal and differentiation," Blood, vol. 100, no. 4, pp. 1302-1309, 2002.

[84] L. Rossi, G. A. Challen, O. Sirin et al., "Hematopoietic stem cell characterization and isolation," Methods in Molecular Biology, vol. 750, part 2, pp. 47-59, 2011.

[85] T. Ishida, M. Hishizawa, K. Kato et al., "Allogeneic hematopoietic stem cell transplantation for adult T-cell leukemialymphoma with special emphasis on preconditioning regimen: a nationwide retrospective study," Blood. In press.

[86] J. P. Fermand, P. Ravaud, S. Chevret et al., "High-dose therapy and autologous blood stem cell transplantation in multiple myeloma: preliminary results of a randomized trial involving 167 patients," Stem Cells, vol. 13, supplement 2, pp. 156-159, 1995.

[87] H. M. Lokhorst, P. Sonneveld, J. J. Cornelissen et al., "Induction therapy with vincristine, adriamycin, dexamethasone (VAD) and intermediate-dose melphalan (IDM) followed by autologous or allogeneic stem cell transplantation in newly diagnosed multiple myeloma," Bone Marrow Transplantation, vol. 23, no. 4, pp. 317-322, 1999.

[88] P. L. McCarthy, K. Owzar, C. C. Hofmeister et al., "Lenalidomide after stem-cell transplantation for multiple myeloma," The New England Journal of Medicine, vol. 366, no. 19, pp. 1770-1781, 2012.

[89] M. Attal, V. Lauwers-Cances, G. Marit et al., "Lenalidomide maintenance after stem-cell transplantation for multiple myeloma," The New England Journal of Medicine, vol. 366, no. 19, pp. 1782-1791, 2012.

[90] A. J. Jakubowiak, K. A. Griffith, D. E. Reece et al., "Lenalidomide, bortezomib, pegylated liposomal doxorubicin, and dexamethasone in newly diagnosed multiple myeloma: a phase 1/2 Multiple Myeloma Research Consortium trial," Blood, vol. 118, no. 3, pp. 535-543, 2011.
[91] A. J. Jakubowiak, T. Kendall, A. Al-Zoubi et al., "Phase II trial of combination therapy with bortezomib, pegylated liposomal doxorubicin, and dexamethasone in patients with newly diagnosed myeloma," Journal of Clinical Oncology, vol. 27, no. 30, pp. 5015-5022, 2009.

[92] J. S. Miller, E. H. Warren, M. R. M. van den Brink et al., "NCI first international workshop on the biology, prevention, and treatment of relapse after allogeneic hematopoietic stem cell transplantation: report from the committee on the biology underlying recurrence of malignant disease following allogeneic HSCT: graft-versus-tumor/leukemia reaction," Biology of Blood and Marrow Transplantation, vol. 16, no. 5, pp. 565-586, 2010.

[93] A. Utsunomiya, Y. Miyazaki, Y. Takatsuka et al., "Improved outcome of adult $\mathrm{T}$ cell leukemia/lymphoma with allogeneic hematopoietic stem cell transplantation," Bone Marrow Transplantation, vol. 27, no. 1, pp. 15-20, 2001.

[94] W. Hasegawa, G. R. Pond, J. T. Rifkind et al., "Longterm follow-up of secondary malignancies in adults after allogeneic bone marrow transplantation," Bone Marrow Transplantation, vol. 35, no. 1, pp. 51-55, 2005.

[95] H. J. Deeg, J. Sanders, and P. Martin, "Secondary malignancies after marrow transplantation," Experimental Hematology, vol. 12, no. 8, pp. 660-666, 1984.

[96] R. F. Wynn, J. E. Wraith, J. Mercer et al., "Improved metabolic correction in patients with lysosomal storage disease treated with hematopoietic stem cell transplant compared with enzyme replacement therapy," Journal of Pediatrics, vol. 154, no. 4, pp. 609-611, 2009.

[97] H. Church, K. Tylee, A. Cooper et al., "Biochemical monitoring after haemopoietic stem cell transplant for Hurler syndrome (MPSIH): implications for functional outcome after transplant in metabolic disease," Bone Marrow Transplantation, vol. 39, no. 4, pp. 207-210, 2007.

[98] E. Shapiro, W. Krivit, L. Lockman et al., "Long-term effect of bone-marrow transplantation for childhood-onset cerebral X-linked adrenoleukodystrophy," The Lancet, vol. 356, no. 9231, pp. 713-718, 2000.

[99] J. Cohen, "The emerging race to cure HIV infections," Science, vol. 332, no. 6031, pp. 784-789, 2011.

[100] J. Yang, Y. Yan, B. Ciric et al., "Evaluation of bone marrowand brain-derived neural stem cells in therapy of central nervous system autoimmunity," The American Journal of Pathology, vol. 177, no. 4, pp. 1989-2001, 2010.

[101] B. A. Reynolds and S. Weiss, "Generation of neurons and astrocytes from isolated cells of the adult mammalian central nervous system," Science, vol. 255, no. 5052, pp. 1707-1710, 1992.

[102] S. Nemati, M. Hatami, S. Kiani et al., "Long-term selfrenewable feeder-free human induced pluripotent stem cellderived neural progenitors," Stem Cells and Development, vol. 20, no. 3, pp. 503-514, 2011.

[103] A. Falk, P. Koch, J. Kesavan et al., "Capture of neuroepitheliallike stem cells from pluripotent stem cells provides a versatile system for in vitro production of human neurons," PLoS One, vol. 7, no. 1, Article ID e29597, 2012.

[104] J. B. Kim, B. Greber, M. J. Arazo-Bravo et al., "Direct reprogramming of human neural stem cells by OCT4," Nature, vol. 461, no. 7264, pp. 649-653, 2009.

[105] C. Varela, J. A. Denis, J. Polentes et al., "Recurrent genomic instability of chromosome 1q in neural derivatives of human embryonic stem cells," The Journal of Clinical Investigation, vol. 122, no. 2, pp. 569-574, 2012. 
[106] N. J. Harrison, "Genetic instability in neural stem cells: an inconvenient truth?" The Journal of Clinical Investigation, vol. 122, no. 2, pp. 484-486, 2012.

[107] S. Pluchino, A. Quattrini, E. Brambilla et al., "Injection of adult neurospheres induces recovery in a chronic model of multiple sclerosis," Nature, vol. 422, no. 6933, pp. 688-694, 2003.

[108] S. Pluchino, L. Zanotti, B. Rossi et al., "Neurospherederived multipotent precursors promote neuroprotection by an immunomodulatory mechanism," Nature, vol. 436, no. 7048, pp. 266-271, 2005.

[109] M. Neri, A. Ricca, I. di Girolamo et al., "Neural stem cell gene therapy ameliorates pathology and function in a mouse model of globoid cell leukodystrophy," Stem Cells, vol. 29, no. 10, pp. 1559-1571, 2011.

[110] M. Aharonowiz, O. Einstein, N. Fainstein, H. Lassmann, B. Reubinoff, and T. Ben-Hur, "Neuroprotective effect of transplanted human embryonic stem cell-derived neural precursors in an animal model of multiple sclerosis," PLoS ONE, vol. 3, no. 9, Article ID e3145, 2008.

[111] S. Pluchino, L. Zanotti, E. Brambilla et al., "Immune regulatory neural stem/precursor cells protect from central nervous system autoimmunity by restraining dendritic cell function,” PLoS ONE, vol. 4, no. 6, Article ID e5959, 2009.

[112] J. Yang, Z. Jiang, D. C. Fitzgerald et al., "Adult neural stem cells expressing IL-10 confer potent immunomodulation and remyelination in experimental autoimmune encephalitis," The Journal of Clinical Investigation, vol. 119, no. 12, pp. 3678-3691, 2009.

[113] F. H. Gage, "Mammalian neural stem cells," Science, vol. 287, no. 5457, pp. 1433-1438, 2000.

[114] A. I. Danilov, R. Covacu, M. C. Moe et al., "Neurogenesis in the adult spinal cord in an experimental model of multiple sclerosis," European Journal of Neuroscience, vol. 23, no. 2, pp. 394-400, 2006.

[115] L. Brundin, H. Brismar, A. I. Danilov, T. Olsson, and C. B. Johansson, "Neural stem cells: a potential source for remyelination in neuroinflammatory disease," Brain Pathology, vol. 13, no. 3, pp. 322-328, 2003.

[116] C. B. Johansson, S. Momma, D. L. Clarke, M. Risling, U. Lendahl, and J. Frisén, "Identification of a neural stem cell in the adult mammalian central nervous system," Cell, vol. 96, no. 1, pp. 25-34, 1999.

[117] B. Saha, M. Jaber, and A. Gaillard, "Potentials of endogenous neural stem cells in cortical repair," Frontiers in Cellular Neuroscience, vol. 6, p. 14, 2012.

[118] T. Shirasaka, W. Ukai, T. Yoshinaga et al., "Promising therapy of neural stem cell transplantation for FASD model-neural network reconstruction and behavior recovery," Nihon Arukoru Yakubutsu Igakkai Zasshi, vol. 46, no. 6, pp. 576-584, 2011.

[119] L. S. Shihabuddin and S. H. Cheng, "Neural stem cell transplantation as a therapeutic approach for treating lysosomal storage diseases," Neurotherapeutics, vol. 8, no. 4, pp. 659667, 2011.

[120] G. Chen, Y. R. Hu, H. Wan et al., "Functional recovery following traumatic spinal cord injury mediated by a unique polymer scaffold seeded with neural stem cells and Schwann cells," Chinese Medical Journal, vol. 123, no. 17, pp. 24242431, 2010.

[121] M. Shackleton, F. Vaillant, K. J. Simpson et al., "Generation of a functional mammary gland from a single stem cell," Nature, vol. 439, no. 7072, pp. 84-88, 2006.
[122] J. Stingl, P. Eirew, I. Ricketson et al., "Purification and unique properties of mammary epithelial stem cells," Nature, vol. 439, no. 7079, pp. 993-997, 2006.

[123] D. Dey, M. Saxena, A. N. Paranjape et al., "Phenotypic and functional characterization of human mammary stem/progenitor cells in long term culture," PLOS ONE, vol. 4, no. 4, Article ID e5329, 2009.

[124] C. M. Dekaney, J. J. Fong, R. J. Rigby, P. K. Lund, S. J. Henning, and M. A. Helmrath, "Expansion of intestinal stem cells associated with long-term adaptation following ileocecal resection in mice," American Journal of Physiology, vol. 293, no. 5, pp. G1013-G1022, 2007.

[125] I. Breuskin, M. Bodson, N. Thelen et al., "Strategies to regenerate hair cells: identification of progenitors and critical genes," Hearing Research, vol. 236, no. 1-2, pp. 1-10, 2008.

[126] H. Li, H. Liu, and S. Heller, "Pluripotent stem cells from the adult mouse inner ear," Nature Medicine, vol. 9, no. 10, pp. 1293-1299, 2003.

[127] I. Dobrinski, "Germ cell transplantation and testis tissue xenografting in domestic animals," Animal Reproduction Science, vol. 89, no. 1-4, pp. 137-145, 2005.

[128] A. Honaramooz, E. Behboodi, S. O. Megee et al., "Fertility and germline transmission of donor haplotype following germ cell transplantation in immunocompetent goats," Biology of Reproduction, vol. 69, no. 4, pp. 1260-1264, 2003.

[129] R. L. Brinster and M. R. Avarbock, "Germline transmission of donor haplotype following spermatogonial transplantation," Proceedings of the National Academy of Sciences of the United States of America, vol. 91, no. 24, pp. 11303-11307, 1994.

[130] M. Tesio, K. Golan, S. Corso et al., "Enhanced c-Met activity promotes G-CSF-induced mobilization of hematopoietic progenitor cells via ROS signaling," Blood, vol. 117, no. 2, pp. 419-428, 2011. 

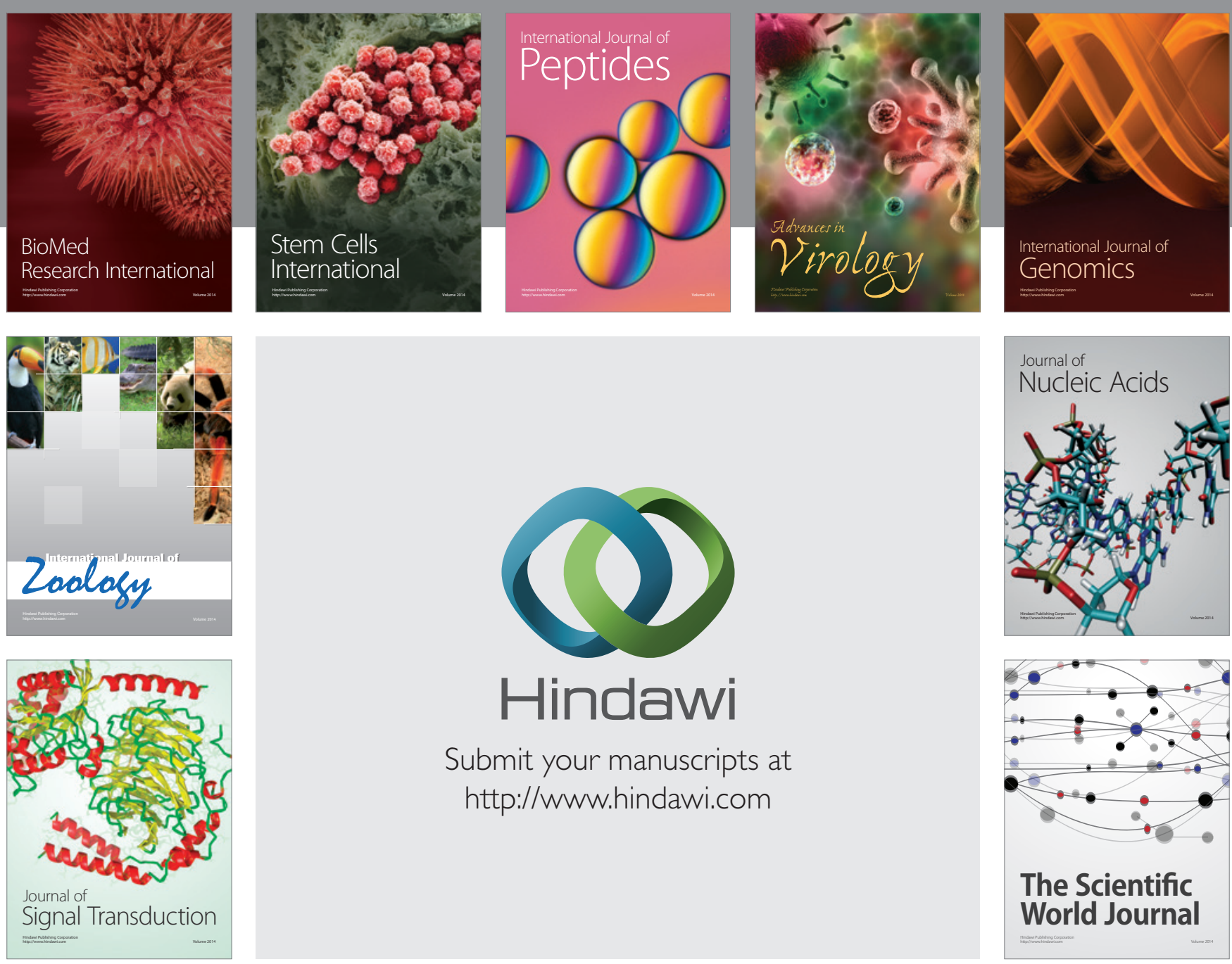

Submit your manuscripts at

http://www.hindawi.com
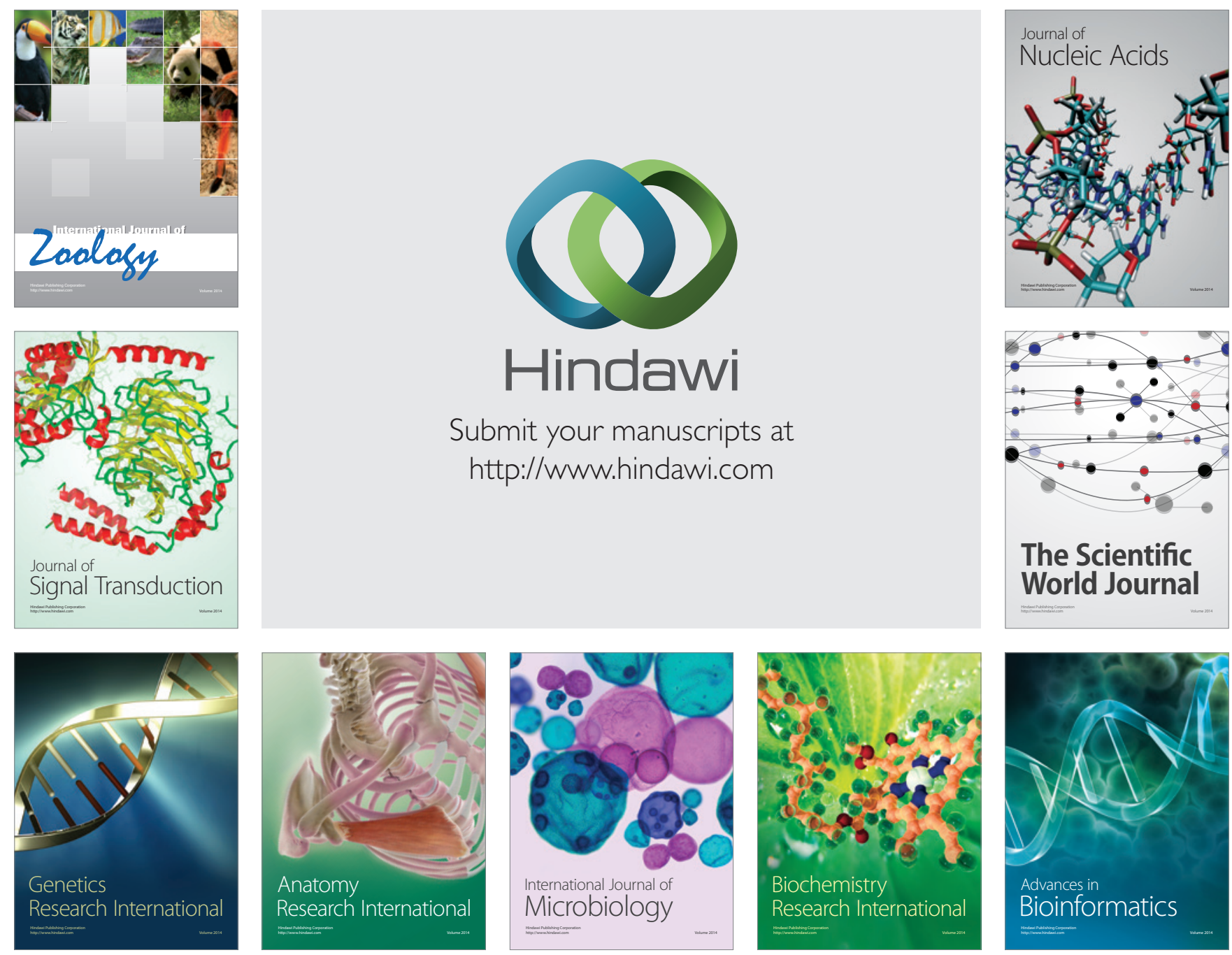

The Scientific World Journal
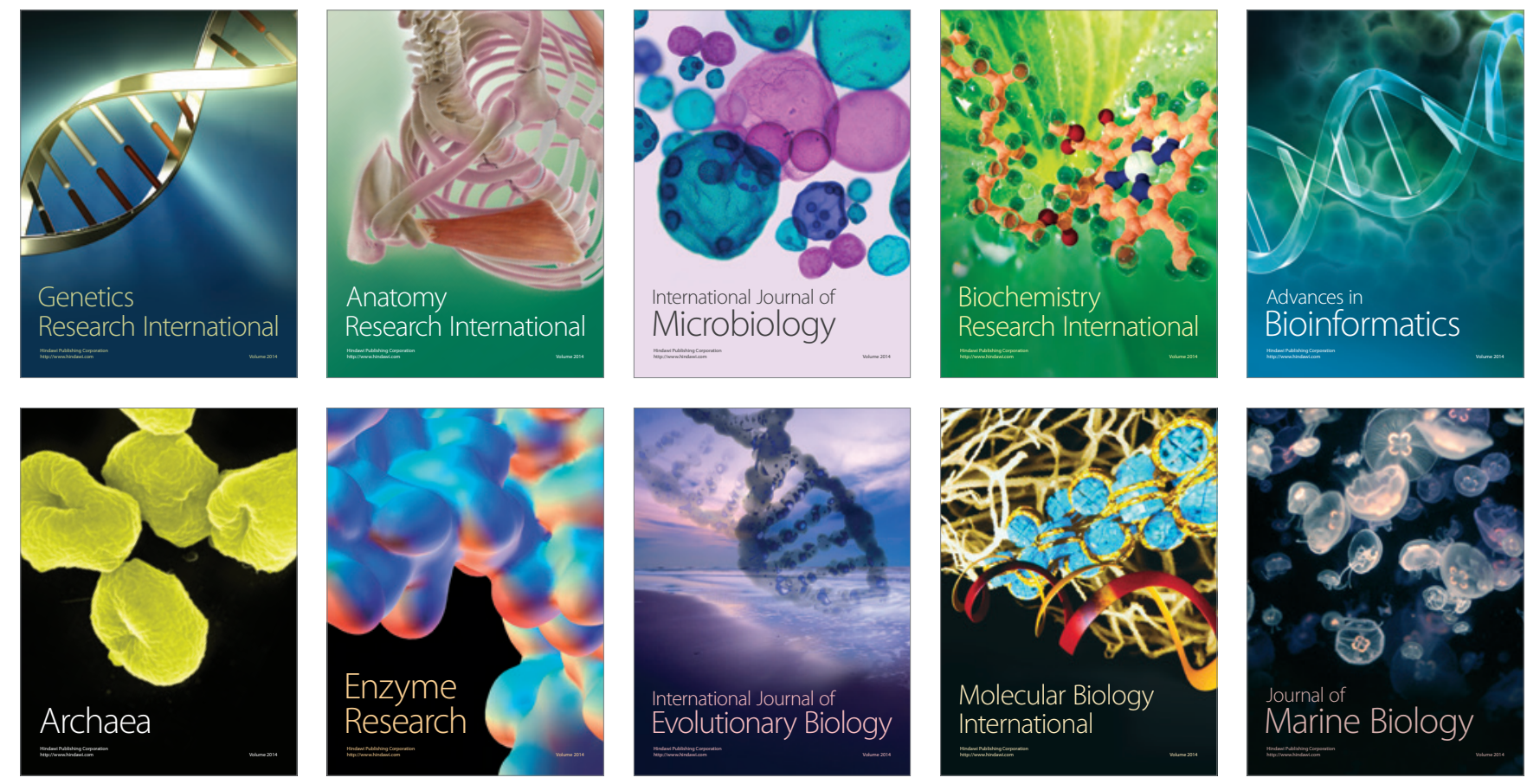